Artigo recebido em

19/03/2014

Aprovado em

27/04/2014

KARINA JANZ

WOITOWICZ

Universidade Estadual de

Ponta Grossa (UEPG) -

karinajw@gmail.com

Professora do Curso

de Jornalismo e do

Mestrado em Jornalismo

da Universidade Estadual de Ponta Grossa (UEPG/

PR), mestre em Ciências

da Comunicação, doutora

em Ciências Humanas,

coordenadora do Grupo de Estudos de Jornalismo e

Gênero da UEPG.

\section{A resistência das mulheres na ditadura militar brasileira: Imprensa feminista e práticas de ativismo}

\author{
Karina Janz Woitowicz
}

\begin{abstract}
Resumo
Discutir o papel da imprensa feminista na tematização dos direitos das mulheres e no processo de organização do movimento feminista no Brasil, no contexto da ditadura militar. Este é o propósito do presente artigo, que parte de uma caracterização dos jornais feministas que circularam entre os anos 1970 e 80 para debater os contrastes entre as lutas gerais, pelo fim do regime autoritário, e as lutas específicas das mulheres, repercutidas nas páginas da imprensa alternativa. As marcas da dupla militância, nos partidos políticos e no movimento feminista, revelam um campo de disputas que ecoa nos jornais, produzindo tensões e provocando desafios para o discurso e a prática feminista, em meio às lutas pela democracia.

Palavras-chave

Imprensa alternativa; movimentos sociais; história da imprensa; ativismo midiático.

Abstract

Discuss the role of feminist press on themes of women's rights and the organization of the feminist movement in Brazil, in the context of military dictatorship. This is the purpose of this article, which starts of a characterization of feminist newspapers that circulated between 1970 and 80 to discuss the contrasts between general fights at the end of the authoritarian regime, and the specific struggles of women, reflected the press alternative. The brands of double militancy, political parties and the feminist movement, reveal a field of disputes that echoes in the newspapers, producing tensions and provoking challenges for feminist discourse and practice, amid the struggles for democracy.
\end{abstract}

Keywords

Alternative press, social movements, history of media, media activism.
Estudos em Jornalismo e Mídia Vol. $11 \mathrm{~N}^{\circ} 1$

Janeiro a Junho de 2014 ISSNe 1984-6924 
1- Céli Pinto assim demarca as diferenças entre um feminismo bem-comportado e um mal-comportado: "O primeiro não afrontava os poderes, mas buscava apoio neles. Não pode ser percebido a partir de uma clivagem de classe social, mas certamente a partir da forma como essas mulheres viviam suas posições de elite econômica e intelectual. O segundo era de enfrentamento: o feminismo "malcriado" expressava-se nas passeatas, nos enfrentamentos na Justiça e nas atividades de mulheres livrepensadoras que criavam jornais e escreviam livros e peças de teatro. Somavam-se a elas as anarquistas radicais que traziam para a discussão o mundo do trabalho, muito distante das preocupações das feministas de elite." (2003, p. 38)

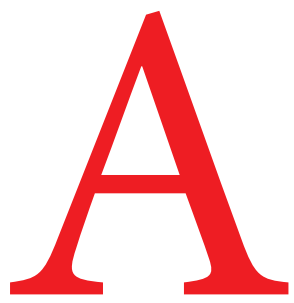

história da imprensa alternativa produzida no período da ditadura militar no Brasil é reveladora do processo de organização da sociedade a partir de grupos e setores que se mobilizam para lutar pela democracia, conjugando uma causa geral - o fim do regime autoritário - com demandas específicas (dos estudantes, trabalhadores, mulheres, homossexuais, etc).

No presente texto, pretende-se discutir o fortalecimento do movimento feminista a partir de suas publicações impressas, servindo como fonte para observação das dinâmicas sociais que marcaram os chamados 'anos de chumbo'.

Para tanto, são trazidas referências sobre a trajetória do feminismo e o papel da mídia alternativa na visibilidade das lutas das mulheres e no próprio processo de organização dos grupos feministas, de modo a situar, na história da imprensa alternativa, o debate entre lutas gerais e específicas que caracterizou os anos 1970 e 80.

Ao traçar algumas informações sobre a história dos veículos feministas e suas bandeiras, a partir de textos publicados nos jornais, busca-se lançar luz sob o processo gradativo de conquista de espaço para tematizar, em meio à ditadura, temas dos direitos das mulheres.

Trata-se de uma história que compõe um cenário de lutas pela resistência, que contou com o papel decisivo da imprensa alternativa para instituir na esfera pública as demandas pela cidadania feminina, conjugada com transformações no campo da política.

\section{$O$ feminismo de segunda onda em meio às lutas pela democracia}

O movimento feminista é caracterizado pela diversidade de vertentes, que transitam entre lutas gerais e específicas promovidas pelas mulheres. Porém, conforme destaca Céli Pinto, o feminismo no Brasil "não foi uma importação que pairou acima das contradições e lutas que constituem as terras brasileiras, foi um movimento que desde suas primeiras manifestações encontrou um campo de luta particular" (2003, p. 10).

A autora divide a trajetória do movimento em fases que denomina de "feminismo bem-comportado" e "feminismo malcomportado". A primeira corresponde ao início do movimento, entre o final de século XIX até o ano de 1932, quando as mulheres conquistam o direito de votar, tendo em Bertha Lutz sua principal expoente.

Já a outra fase diz respeito a um posicionamento mais 'radical' em relação à dominação masculina, em que figuram desde mulheres intelectualizadas que escreviam em jornais até líderes operárias. Para Céli Pinto, de 1932 até as primeiras manifestações nos anos 1970 é considerado um período de refluxo do movimento feminista, em que havia pouco espaço para as chamadas lutas "particularistas" (2003, p. 10).

Assim, da primeira vertente, marcada pelos direitos políticos, o feminismo no Brasil - caracterizado como de segunda onda ${ }^{2}$ - ressurge na década de 1970 , em meio ao período mais radical contra a ditadura militar, contando com a participação de mulheres que passaram 
pela experiência do exílio. De acordo com Elizabeth Cardoso,

Com os "anos de chumbo" da ditadura militar, várias mulheres brasileiras seguiram para o exílio e uma vez fora do Brasil elas fundaram grupos feministas no exterior. Quatro deles ganharam destaque: o Comitê de Mulheres Brasileiras no Exterior, criado por Zuleika Alembert, no Chile, durante os dois primeiros anos da década de 1970; grupo de autoconsciência, fundado por Branca Moreira Alves, em Berkeley, Estados Unidos, no início dos anos 70; o Círculo de Mulheres Brasileiras em Paris, fundado em abril de 1976, por um grupo de mulheres brasileiras, e o Grupo Latino-Americano de Mulheres em Paris, fundado por Danda Prado, na França, em 1972. (2004, p. 41)

Joana Pedro (2006) destaca que a prática dos grupos de reflexão, criados pelas mulheres que tiveram contato com o feminismo nos Estados Unidos, era vista com hostilidade por determinados setores de esquerda, que apostavam em outras frentes de luta e consideravam inúteis tais discussões, devido ao seu viés "pequeno-burguês": "os grupos de reflexão, as lutas pelo controle e autonomia do corpo, sexualidade, as manifestações pela liberação da mulher, eram consideradas "ideias específicas", e portanto divisionistas da luta geral que consideravam ter prioridade: pela democratização, pela anistia, pelo socialismo" (2006, p. 16).

Para além destes impasses e dificuldades que acompanharam o processo de fortalecimento do feminismo, é preciso reconhecer a atuação de diversos grupos na luta pela superação das desigualdades entre homens e mulheres, que garantiram a legitimidade do movimento. Neste sentido, os anos 1970 registram uma série de conquistas relacionadas à participação das mulheres no meio social e ao comprometimento com as reivindicações e causas feministas.

Surgem vários grupos de consciência e em 1975, estimuladas pela instituição do Dia Internacional da Mulher pela ONU - Organização das Nações Unidas, ocorrem reuniões no Rio de Janeiro e em São Paulo, que resultaram na criação do Centro da Mulher Brasileira (Rio) e do Centro de Desenvolvimento da Mulher Brasileira (São Paulo). Em 1979, acontece o Primeiro Encontro Nacional de Mulheres e, na década de 1980, já existem dezenas de grupos feministas por todo país.

De acordo com Maria Amélia de Almeida Telles (1999), este é o momento em que as mulheres deixam de apenas marcar presença nos movimentos sociais ao lado dos homens (só para se ter uma ideia, o Comitê Brasileiro de Anistia calcula que cerca de $12 \%$ das integrantes de movimentos sociais eram mulheres), e

\section{Publicações feministas}

discutiam aspectos e tendências do movimento em temáticas como trabalho e política

começam a surgir lutas mais dirigidas.

Em decorrência das lutas promovidas pelas mulheres, surgem vários clubes de mães, que começam a levantar discussões
2- Entre as fases do feminismo, considerase a primeira onda (marcada pela conquista de direitos políticos) e a segunda onda (em que as lutas se voltam à conquista de direitos civis e culturais). Esta última ganha força nos anos 1970, com diversas organizações de mulheres e lutas que envolvem o direito ao corpo. Esta é a classificação usada por Joana Maria Pedro (2006) e outras pesquisadoras. 
sobre custo de vida, baixos salários, creches para mães trabalhadoras, sexualidade, violência sexual e doméstica. São realizados congressos de mulheres, marchas, cartas às autoridades exigindo mudanças, entre outras ações, e começam a ganhar espaço lutas feministas como o direito ao corpo e sexualidade. E é neste contexto de mobilização que a imprensa feminista surge como espaço de resistência e luta das mulheres.

3- Para situaro contexto em que tais discursos se inscrevem, é importante lembrar que a ditadura militar (19641984) representou um período de autoritarismo político que permaneceu por duas décadas, entrando para a história do País como os chamados "anos de chumbo": censura, repressão armada, perseguições, manobras políticas, entre outras práticas características deste regime, marcaram o período. Em meio a este sistema de castração de direitos e controle à liberdade de expressão, surgem centenas de publicações, conhecidas como imprensa alternativa, que ousavam denunciar situações de opressão. Defendendo interesses de diversos movimentos sociais, a imprensa alternativa proporcionou $o$ debate de idéias, fazendo circular informações que, de outro modo, seriam silenciadas, criando espaços de disputa de hegemonia.

\section{Mídia alternativa e ativismo feminista}

Embora a história do movimento de mulheres registre a existência de diversas iniciativas de imprensa feminina e feminista, entre os séculos XIX e XX, pode-se dizer que o momento mais significativo desta trajetória, que contou com a participação da mídia alternativa, situa-se nas experiências de comunicação que acompanharam a segunda onda do feminismo no Brasil, em plena ditadura militar. Diante da criação de grupos feministas no país, surgem publicações entre o final dos anos 1970 e o início dos 80 que, com orientações editoriais distintas, inserem o debate sobre diversas questões feministas nos meios da política, da intelectualidade e em setores de base. ${ }^{3}$

É a partir da necessidade de instaurar o diálogo e provocar mudanças que o movimento feminista busca seu fortalecimento e representatividade, organizando-se de forma mais sistemática, levantando bandeiras específicas e se somando à resistência à ditadura militar. Neste período, em que a imprensa alternativa atuou como uma importante aliada para a conscientização de diferentes setores da sociedade, surgem as publicações do movimento feminista, que discutiam aspectos e tendências do movimento a partir de temáticas como trabalho feminino, participação política, liberdade sexual, igualdade de direitos, aborto, políticas públicas para as mulheres, condições de trabalho, violência, entre outras.

As experiências dos grupos feministas e de mulheres apontavam cada vez mais para a necessidade de criar um discurso próprio, capaz de fazer questionamentos e promover mudanças. Em um Encontro do Movimento das Mulheres no Brasil, realizado no Rio de Janeiro em agosto de 1981, entre as temáticas discutidas ganhava destaque a comunicação. O evento, transcrito no livro Mulheres em Movimento, discutiu o papel educativo dos meios de comunicação, considerando que cumprem "não apenas o seu sentido conservador de reprodução da ideologia dominante, mas também, o seu sentido de mudança enquanto focos de resistência e propagadores das novas ideias e valores" (BARSTED, 1983, p. 13).

Ao abordar a importância da criação ou reapropriação da mídia, Leila Barsted observa que na década de 1970 novos espaços foram surgindo para dar voz às mulheres, a partir de meios variados: revistas, boletins, jornais alternativos, luta por espaço dentro da grande imprensa, do rádio, da televisão e do cinema. Para ela, "os veículos de comunicação se apresentam inseridos numa estratégia de educação do movimento feminista, de recriação da identidade social da mulher e de resgate de nossa história." (1983, p. 16)

A necessidade de uma imprensa feminista própria colocou-se, assim, a partir da consciência de que os meios tradicionais de 
comunicação, esfera de atuação dos donos do poder, e até mesmo alguns setores da imprensa alternativa, ou ignoram a mulher, ou reforçam os estereótipos discriminatórios a seu respeito, ou a manipulam enquanto objeto de consumo-consumidora. Ou seja, negam a existência de um falar feminino e, portanto, de uma mulher sujeito de sua fala e de seu desejo. (1983, p. 14)

Entre as experiências de imprensa alternativa feminista ${ }^{4}$, destacam-se os jornais Brasil Mulher (1975-1979), Nós Mulheres (1976-1978) e Mulherio (1981-1987), que tiveram uma inegável contribuição para o debate em torno da necessidade de enfrentar novos desafios em uma sociedade marcada pela diferença e pela desigualdade entre os sexos, fortalecendo diversas reivindicações do movimento feminista.

Além destes veículos, existiram muitas outras experiências do movimento de mulheres e feministas, como os jornais Maria Quitéria (1977) $)^{5}$ Correio da Mulher (1979), Liberta (Porto Alegre, 1980), Chanacomchana (do grupo de ação lésbico-feminista, 1982), Mulher $A B C$, o goiano Mariação, as revistas Fotochoq e Maria Sem Vergonha, o programa de rádio Mulher em 360 (Rádio Capital/ $\mathrm{SP}$ ), o programa Elas e mais elas" (Rádio Solimões) e diversos outros criados por grupos feministas em diferentes regiões do País.

Percebe-se que o movimento feminista, na medida em que se constitui como um espaço de resistência e luta em defesa das mulheres, passa a incorporar em suas ações diversas práticas relacionadas aos processos midiáticos. Os jornais, a partir de orientações distintas (que circulam entre o enfoque político, a luta de classes e questões ligadas à desigualdade entre homens e mulheres), promovem o debate sobre as causas do feminismo a partir da publicização de determinados assuntos na esfera pública. Lamentavelmente, a maioria dos jornais feministas não oferece informações no expediente sobre a tiragem, a circulação e até mesmo a periodicidade das publicações, dados esses que poderiam apresentar mais elementos para caracterizar a sua abrangência no período considerado. Contudo, é possível encontrar algumas pistas nos textos dos jornais, que indicam as conquistas e as dificuldades encontradas para manter as publicações, bem como as orientações editoriais que as identificam.

Em sua análise das origens da imprensa feminista brasileira, com os jornais Brasil Mulher e Nós Mulheres, Rosalina de Santa Cruz Leite (2003) assim descreve o contexto em que os jornais se desenvolveram:

Mulheres que se auto-organizam nas periferias, em busca da garantia de direitos sociais, e as feministas preocupadas com a emancipação feminina, a discriminação, a sexualidade, o poder, reinventando uma nova forma de fazer política junto com a luta reivindicativa das classes populares. Só assim podese entender o papel desempenhado pelos jornais Brasil Mulher e Nós Mulheres nessa conjuntura. (2003, p. 238)

A mesma autora observa que as feministas que participaram dos referidos jornais eram majoritariamente militantes oriundas da esquerda. Este aspecto da dupla militância é assim descrito na formação dos jornais Brasil Mulher e Nós Mulheres:

[...] O Brasil Mulher já era conhecido pelas feministas exiladas militantes do Círculo de Mulheres de Paris.
4- Antes mesmo das primeiras iniciativas de comunicação alternativa no Brasil, registra-se a participação de brasileiras exiladas em experiências de imprensa feminista durante a ditadura militar. Neste sentido, destaca-se a edição do periódico

Nosotras (19741976), do Grupo Latino-Americano de Mulheres em Paris, fundado por Danda Prado, na França, em 1972.

5- Maria Quitéria surgiu para divulgar as atividades do Movimento Feminino pela Anistia, não podendo ser caracterizado como um jornal. A este respeito, ver: RAMOS, Andressa Maria Vilar. A liberdade permitida. Contradições, limites e conquistas do movimento pela anistia: 1975 1980. Dissertação (Mestrado em História), Pontifícia Universidade Católica de São Paulo, São Paulo, 2002, p. 57. 
6- O jornal foi fundado por Joana

Lopes em Londrinal PR. Pago com o salário da jornalista, o BM foi impresso nas oficinas da Folha da Manhã e levado para são Paulo dentro de uma mala de viagem (KUCINSKI, 2003, p.

125). Lançado com o apoio do Movimento Feminino pela Anistia (MFA), criado no mesmo ano (1975) por Therezinha Zerbini, o jornal foi transferido, a partir da sua segunda edição, para São Paulo.

7- Ao longo de sua existência, foram publicadas 16 edições regulares e mais quatro 'extras'.
A correspondência e o diálogo eram frequentes entre a direção do jornal e o coletivo de mulheres exiladas, de onde se origina grande parte das militantes do Nós Mulheres. E, mais, o Brasil Mulher já era sabidamente, nessa época, constituído por mulheres militantes do Partido Comunista do Brasil (PC do B), da Ação Popular Marxista Leninista (APML) e do Movimento Revolucionário 8 de Outubro (MR8). Quanto ao Círculo de Mulheres de Paris, cabe dizer que era formado por feministas de esquerda integrantes, em sua maioria, do Debate, dissidência política que surge no exílio agrupando exmilitantes da Vanguarda Popular Revolucionária (VPR), da Vanguarda Armada Revolucionária Palmares (VAR-Palmares) e do Partido Comunista Brasileiro (PCB) e mulheres autônomas. Ao voltar ao Brasil, esse segmento lança o Nós Mulheres. (LEITE, 2003, p. 235-236)

Rosalina de Santa Cruz Leite (2003, p. 237) observa que os dois jornais refletem um "período histórico muito intenso e marcado por transformações rápidas e profundas" e destaca como características das publicações as marcas da autonomia e da contestação à ordem social da época, colocando-se de maneira independente do Estado e dos partidos políticos.

\section{Impasses da dupla militância nos jornais feministas}

Para compreender o modo como os grupos feministas se expressam por meio dos jornais, torna-se interessante recuperar os editoriais publicados nas primeiras edições, em que o comprometimento com as causas do movimento se revela. No Brasil Mulher, primeiro jornal dirigido às mulheres e feito por mulheres, publicado pela Sociedade Brasil Mulher ${ }^{6}$, o destaque é para o discurso da igualdade e das lutas pelas causas democráticas, que envolvem homens e mulheres ${ }^{7}$. Segundo Elizabeth Cardoso, o Brasil Mulher:

É o primeiro jornal feminista brasileiro feito no Brasil e traz a gênese do debate entre mulheres feministas e mulheres militantes de esquerda: a situação clássica de dupla militância do movimento feminista no período de 1974 a 1980. Editado bimestralmente, em formato tablóide, contendo 16 páginas em preto-e-branco e ilustrado com fotos, item muito valorizado pela publicação, o Brasil Mulher tinha tiragem de 10 mil exemplares, com circulação nacional e venda em bancas, livrarias e por assinatura. Sua publicação cessa em março de 1980. (2004, p. 43)

O enfoque nas questões de classe é a tônica do jornal, que se revela na maior parte das suas edições. As contradições ou impasses da dupla militância manifestamse logo na primeira edição, diante de um editorial que causou polêmica ao anunciar que o Brasil Mulher "não é um jornal da mulher". O editorial do jornal esclarece sobre esta postura:

Não é o jornal da mulher. Seu objetivo é ser mais uma voz na busca e na tomada da igualdade perdida. Trabalho que se destina a homens e mulheres. Não desejamos nos amparar nas diferenças biológicas para desfrutar de pequenos favores masculinos, ao mesmo tempo que o Estado, constituído de forma masculina, deixa-nos um lugar só comparado ao que é destinado por incapacidade de participação do débil mental. Queremos falar dos problemas que são comuns a todas as mulheres do mundo. Queremos falar também das soluções encontradas 
aqui e em lugares distantes: no entanto, queremos discuti-las em função de nossa realidade brasileira e latino-americana.

(...) Finalmente, Brasil Mulher deseja incorporar-se à imprensa democrática que, em meio à batalhas, o Brasil vê surgir. Teremos um número mensal e a sustentação desta proposta de comunicação depende unicamente da participação daqueles que com ela se identificarem. (BM, ano $1, \mathrm{n}$. 0,9 de out.1975, p. 2)

O reconhecimento como um jornal feminista ocorreu mais tarde, quando reivindicações específicas passaram a ser enfatizadas no periódico. ngela Borba (1983) assim menciona os impasses presentes no período de reformulação do movimento, quando temas como sexualidade assumiam sua importância:

O jornal Brasil Mulher era uma espécie de elo que nos articulava. $\mathrm{O}$ último jornal saiu em março de 1980. Passávamos por um outro processo de questionamentos de nossas concepções sobre o feminismo. A discussão era principalmente sobre a ligação do específico, a questão específica da mulher, com as questões gerais da sociedade. Passávamos nesse momento, também, por uma reformulação que a meu ver tinha relação com o próprio crescimento do movimento de mulheres no Brasil, que nos permitia avançar e assumir com mais destaque questões tais como a sexualidade da mulher. (1983, p. 199)

O Brasil Mulher informa uma tiragem inicial de 5.000 exemplares e, em março de 1979, anuncia a publicação de 10.000 exemplares. Além disso, em sua quinta edição, conta aos leitores e leitoras que está sendo feito com o dinheiro da sua venda, comemorando assim o sucesso do jornal na conquista de assinaturas em diversos estados brasileiros, de colaboradores/as nas suas edições e de uma sede em São Paulo. É o que mostra o seguinte editorial:

A 9 de outubro de 1975 surgia, em Londrina - Paraná, o número 0 do jornal Brasil Mulher com a proposta de ser uma voz na busca e na tomada da igualdade perdida, trabalho destinado a homens e mulheres.

Em um ano de existência, com muito trabalho e sacrifício, o $\mathrm{BM}$ já está se firmando como jornal. Da equipe inicial de cinco mulheres contamos, hoje, com a participação de cerca de 50 pessoas, entre homens e mulheres, em vários estados e também no exterior. (Brasil Mulher, ano 1, n. 5,1976 , p. 2)

Já o Nós Mulheres ${ }^{8}$, lançado um ano depois, tendo como jornalista responsável Anamárcia Veinsecher, se assume como feminista e enfatiza o comprometimento com questões específicas das mulheres, a partir das quais desenvolve, ao longo da sua existência, um importante trabalho com mulheres de classes populares. De acordo com Bernardo Kucinski (2003, p. 128), o jornal possuía "uma base de ativismo mais ampla do que a do Brasil Mulher, incluindo membros de clubes de mães engajadas em lutas por creches na zona sul de São Paulo". Sua matriz ideológica, segundo ao autor, era “o paradigma clássico das esquerdas, mas com autonomia clara para a luta feminista" (KUCINSKI, 2003, p. 128).

Nas suas páginas, revela-se o comprometimento contra a opressão de sexo e de classe, e a defesa do feminismo da igualdade. A proposta do jornal é assim apresentada no primeiro editorial:

Desde que nascemos, NÓS MULHERES ouvimos em casa, na escola, no trabalho, na rua, em
8- Foram publicadas 8 edições do jornal, no período de 1976 a 78 , mantendo a periodicidade bimestral. 
todos os lugares, que nossa função na vida é casar e ter filhos. Que NÓS MULHERES não precisamos estudar nem trabalhar, pois isto é coisa pra homem. (...) NÓS MULHERES decidimos fazer este jornal feminista para que possamos ter um espaço nosso, para discutir nossa situação e nossos problemas. E, também, para pensarmos juntas nas soluções. (Nós Mulheres, ano 1, n. 1, junho de 1976, p. 2)

A respeito da linguagem do Nós Mulheres, Rosalina Leite (2003, p. 239) destaca que se trata de um formato pessoal e afetivo, que revela intimidade: "rompe com o tratamento dado às mulheres pela imprensa feminina tradicional, em que um editor impessoal e assexuado dita regras e 'aconselha' uma leitora chamada de 'você, mulher"'. Este é o tom presente no editorial citado, que projeta a identificação com um sujeito coletivo - as mulheres. O jornal, que circulou de 1976 a 78 , não informa sua tiragem. Porém, sabe-se que sua circulação era voltada para os grupos de mulheres de São Paulo. No editorial abaixo, o Nós Mulheres revela seu comprometimento contra a opressão de sexo e classe:

Que as coisas fiquem claras: mantemos a firme convicção de que existe um espaço para a imprensa feminista, que denuncia a opressão da mulher brasileira e luta por uma sociedade livre e democrática. Acreditamos que a liderança da luta feminista cabe às mulheres das classes trabalhadoras que não só são oprimidas enquanto sexo, mas também exploradas enquanto classe. No Brasil, dada a incipiência da organização de todos que lutam por uma sociedade democrática e, em particular, da organização das mulheres, essa liderança ainda não foi assumida. E esse é o grande desafio que enfrentamos. (Nós Mulheres, n. 7, março de 1978, p. 2)
Nós Mulheres sofria para se manter diante das dificuldades econômicas e em alguns momentos chegou a anunciar campanhas para conseguir doações e assinaturas, contando com a colaboração de outros veículos da imprensa alternativa. Estas dificuldades, e as alternativas encontradas para manter o jornal em circulação, são relatadas no texto abaixo, sob o título "Nós Mulheres agradece":

A gente estava mesmo sem dinheiro. Devendo e sem saber como fazer este número. Nisso, veio a ideia de dar uma festa, não só para comemorar um ano de jornal, o que já é um heroísmo, como também para nos tirar do "buraco".

Nos preparamos durante um mês e no dia 23 de julho, uma festa estava montada na Fundação Getúlio Vargas. Exposição de gravuras, quadros, desenhos, fotos. Venda de livros, discos. Música ao vivo, com conjuntos de chorinho e samba rasgado. Um filme para os mais intelectuais e, para animar, salgadinhos e vinho. Era uma quintafeira e o dia coincidia com o jogo do Brasil - ficamos com medo de não aparecer ninguém, afinal, futebol é futebol. Mas no fim, vieram umas 500 pessoas e apesar do trabalho foi uma noite animada e de muita solidariedade com o Nós Mulheres.

(...) O resultado foi que conseguimos liquidar nossas dívidas e ainda nos sobrou dinheiro para lançar este e o próximo número. Verdade que não resolvemos de vez nosso problema financeiro, mas a solidariedade nos fez avançar mais um pouquinho. (Nós Mulheres, ano 2, n. 6, agosto/ setembro de 1977)

Este aspecto da dificuldade financeira enfrentada pela imprensa feminista é mencionado por Rosalina Leite (2003, p. 237), que analisa que a periodicidade do Brasil Mulher e do Nós Mulheres foi prejudicada pelas dificuldade de conciliar a publicidade com os objetivos de 
militância. Além das campanhas de apoio aos jornais, ambos propagandeavam os demais órgãos da imprensa alternativa, o que denotava o esforço para fortalecer estes espaços, comum entre os veículos que circularam durante a ditadura militar: "leia a imprensa democrática", anunciavam os jornais.

De modo geral, a situação financeira dos jornais, durante toda sua existência, foi muito precária. É ilustrativo que o Brasil Mulher e o Nós Mulheres passem a publicar pequenas notas incentivando a colaboração mensal, com o objetivo de sensibilizar as leitoras para a necessidade de não só comprar e divulgar os jornais mas também de apoiá-los financeiramente a partir do aumento do número de assinantes e daqueles colaboradores que o Brasil Mulher denominava de sócios honorários, que mensalmente colaboravam com uma quantia fixa. (2003, p. 237)

Leite destaca que os dois jornais se assemelham em sua orientação política, tentando conciliar as lutas gerais $\mathrm{e}$ específicas que marcaram a trajetória do feminismo como um movimento social que se consolida em um período de crise política.

Durante o tempo de sua existência, os dois jornais reafirmam constantemente sua identidade feminista, porém o fazem geralmente na defensiva, argumentando que o feminismo não separa a luta pela emancipação das mulheres da luta pela emancipação humana, que a luta das mulheres não é contra os homens, mas a favor de novas relações igualitárias, etc. (2003, p. 239)

Em uma conjuntura política um pouco mais aberta ao diálogo sobre questões específicas das mulheres, e menos marcada pela militância de esquerda, surge em São Paulo, no início de 1981, o jornal Mulherio, como a concretização de um antigo projeto de algumas pesquisadoras da Fundação Carlos Chagas, que se dedicavam ao estudo da condição feminina no Brasil ${ }^{9}$. Fundado por Adélia Borges ${ }^{10}$ e conhecido como "o mais duradouro e o mais feminista dos jornais feministas" (KUCINSKI, 2003, p. 129), Mulherio fugia do modelo organizativo da imprensa alternativa dos anos 1970, contando com o suporte de uma entidade.

\section{O jornal não era ligado a nenhum grupo} feminista em particular; ele era formado por mulheres de vários grupos e dava destaque para questões relacionadas a comportamento e sexualidade, sendo publicadas 39 edições. Em um texto assinado por Adélia Borges, o jornal anuncia diversas apoiadoras em todo país:

Era apenas um folheto, despretensioso, anunciando $\mathrm{o}$ lançamento de um jornal. Mas a repercussão que o número zero de Mulherio alcançou surpreendeunos, como a demonstrar que a mulher brasileira precisa realmente de um veículo de comunicação que divulgue suas coisas de uma forma nova, nossa. (Mulherio, ano 1, n. 1, maio/junho de 1981)

Em um texto sobre o Mulherio, Adélia Borges relata o crescimento do jornal e a sua repercussão entre as mulheres, feministas ou não. Ela conta que o jornal era distribuído gratuitamente para instituições, emissoras de televisão e rádio do país e também para entidades acadêmicas, grupos feministas, etc. Além disso, "alguns jornais de bairro e do interior de São Paulo reproduzem em
9- Em 1988, o jornal Nexo - Feminismo, Informação e Cultura é criado em substituição ao Mulherio. No editorial da primeira edição, assinado por Inês Castilho, o Nexo mostra a que veio: "Refletindo as transformações vividas pelo

feminismo em todo o mundo e largamente discutidas,

"Mulherio" dá lugar a "Nexo", mantendo sua identidade e religando-se ao universo mais amplo para responder à necessidade de um espaço plural de reflexão e criação no deserto brasileiro".

(Nexo, n. 1, junho de 1988)

10- Bernardo Kucinski lembra que Adélia Borges havia trabalhado em Movimento "e posta na lista negra das grandes empresas jornalísticas, depois de participar da greve dos jornalistas de 1979, como dirigente sindical" (2003, p.

129). 
parte ou inteiramente o jornal Mulherio. Algumas rádios do interior chegam mesmo a ler o jornal todo" (1983, p. 24), o que demonstra que estas publicações circulavam de outros modos, além das assinaturas, chegando a um público mais amplo.

Nosso jornal tem periodicidade bimensal e o terceiro número saiu com tiragem de 8.000 exemplares. Isto está tendo uma penetração muito grande. O que me surpreendeu é que o jornal está servindo para levar a causa feminista; para levar a preocupação com a condição da mulher para pessoas que, pelo menos me parece, pelas cartas que escrevem, não tinham essa preocupação anteriormente. A correspondência que chega lá é muito grande. Uma média de 5 a 10 cartas por dia, de pessoas dos mais variados cantos do país, cidades que eu até nunca sabia os nomes. Estamos muito entusiasmadas com a penetração do jornal. Temos visto o que ele está conseguindo fazer até agora. Tem circulação nacional e vai também para grupos de mulheres no exterior. Funciona mais com sistema de assinaturas, que está custando agora (1981), 300 cruzeiros anuais. Em julho de 1981, nós estávamos com mais de 400 assinaturas, só esse mês. Então estamos crescendo bastante. (1983, p. 22)

O Mulherio, que também mantinha uma periodicidade bimestral, foi o jornal feminista de maior duração, sendo publicado por seis anos. Embora a tiragem do jornal não conste na maioria das edições, em uma das publicações, de 1984, encontra-se a referência a uma tiragem de 12 mil exemplares. Ao longo de sua existência, o jornal ficou por sete meses fora de circulação, quando a Fundação Carlos Chagas (SP) retirou o apoio financeiro. O Mulherio retornou em função da necessidade de servir como um espaço de debate sobre o feminismo. Neste momento, o jornal explica a alternativa encontrada para se manter em circulação.

(...) Ele volta agora porque, ao anunciarmos nos dois últimos números o fim próximo, recebemos uma calorosa manifestação de solidariedade de centenas de leitores de todo o País, de cidades grandes e de cidades pequenas, de gente "importante" e de gente anônima, de mulheres e de homens também.

Foi isso que nos motivou a continuar tentando. Sem recursos próprios, buscando apoio em agências internacionais que financiam projetos ligados à promoção da mulher. E recebemos esse apoio pequeno em dinheiro, mas suficiente para dar a arrancada inicial nesta nova fase do Mulherio. (Mulherio, ano 4, n. 16, maio/junho de 1984)

Além de experiências que dizem respeito a grupos que se formaram a partir da criação de um veículo, o que se destacam no período são as iniciativas de produção de jornais como uma prática comum de diversos grupos feministas. Muitas vezes de forma artesanal e com poucos recursos, estes veículos eram publicados com o firme propósito de divulgar a causa feminista, dentro e fora do movimento. Exemplos destas experiências são os jornais Agora é que são elas, do Círculo de Mulheres Brasileiras, publicado por exiladas brasileiras em Paris em 1975, e Brasília Mulher, do Grupo Brasília Mulher, de 1982.

Outra publicação que marca o período de consolidação das lutas específicas das mulheres é o ChanacomChana, publicado em 1981 pelo Movimento Lésbico-Feminista (MLF). O movimento era formado por mulheres dissidentes do Grupo Somos, fundado em 1978, 
conhecido como primeiro grupo homossexual politicamente organizado no Brasil.

Segundo Elizabeth Cardoso, "com tiragem de, em média, 200 exemplares por edição e periodicidade instável, entre trimestral e quadrimestral, o ChanacomChana circulou durante toda a década de 80 , com sua última edição publicada no ano de 1989 (2004, p. 46). A publicação, produzida de forma artesanal, se assemelhava a um fanzine e simbolizava a aproximação entre lésbicas e feministas.

Também é preciso destacar que as questões feministas encontravam espaço em outros veículos alternativos que circularam durante o período da ditadura militar (tais como Opinião, Movimento, Repórter, Pasquim, Coojornal, Versus, Beijo, Bagaço, Em Tempo, Lampião, Informação, Ovelha Negra, Escrita, Cobra de Vidro, De Fato, entre diversos outros ${ }^{11}$ ). Estas publicações reuniam reivindicações de grupos sociais que não encontravam

\section{Os rigores da censura se impuseram e}

\section{comprometeram}

\section{a circulação de}

\section{informações sobre a} Iuta pela democracia

espaço nos veículos tradicionais para se expressar, estabelecendo vínculos de solidariedade entre os diferentes grupos e movimentos que integravam a luta pela democracia. Obviamente, a censura tentava barrar qualquer tipo de oposição ideológica, o que incluía o feminismo e suas expressões. Exemplo disso é uma edição do jornal Movimento sobre a censura (12 de junho de 1978), em que consta uma reportagem sob o título "É proibido falar de mulheres", revelando vários momentos em que houve a proibição de temas ligados à mulher, principalmente no que se refere a uma edição especial sobre as mulheres, que foi apreendida pelos censores:

O Dia Internacional da Mulher estava próximo. Numa das reuniões de pauta decidimos que era necessária uma edição especial, onde pudesse aprofundar os debates em torno do papel da mulher no Brasil (...). O esforço foi realmente grande - cerca de 40 jornalistas participaram do trabalho e o resultado, extraordinário: o mais completo levantamento, em termos de pesquisa e reportagens já feito no país em torno do tema. O contraesforço da censura, no entanto, não foi menor: praticamente vetou tudo, 337 laudas de texto, 65 ilustrações. Mais de $80 \%$ do material enviado; um corte como nunca havíamos visto antes, suficiente para produzirmos um livro de 250 páginas. (Movimento, 12 jun. 1978)

Os rigores da censura se impuseram aos grupos organizados e comprometeram a circulação de informações sobre a luta pela democracia e as outras lutas específicas empreendidas por diferentes setores da sociedade na reivindicação de direitos. O conservadorismo em torno de temas ligados a questões culturais e comportamentais, aliado ao controle político da informação, impôs filtros para tematizar as mulheres nos jornais, desafiando a mídia alternativa a produzir discursos contrastantes a respeito dos direitos das mulheres.
11- Sobre a presença das lutas feministas na imprensa alternativa (nos jornais Opinião, Movimento e Repórter), ver artigo publicado pela autora no livro Recortes da mídia alternativa: histórias \& memórias da comunicação no Brasil. (WOITOWICZ, 2009). 


\section{Considerações Finais}

Apesar do controle expressivo dos militares, a imprensa alternativa proporciona um amplo debate acerca das lutas das mulheres, principalmente no que diz respeito às operárias e aos chamados setores de base. Ao folhear os jornais, é possível encontrar muitas ocorrências sobre greves, reivindicações por creches para mães trabalhadoras, notícias sobre as presas políticas, bem como informações sobre o movimento de mulheres (eventos, documentos, mobilizações, etc), que indicam a representatividade que $o$ feminismo assumiu em meio às lutas que marcaram o referido período.

Porém, esta solidariedade nem sempre se mostrou plena e irrestrita, pois ao mesmo tempo em que a imprensa alternativa dava espaço para as causas feministas e assumia a defesa dos direitos das mulheres, por vezes recaía em contradições, próprias das disputas no interior do movimento de esquerda e das questões de gênero implicadas nas reivindicações das mulheres. Céli Pinto faz a seguinte observação sobre o modo como o feminismo era visto na época:

O feminismo era malvisto no Brasil, pelos militares, pela esquerda, por uma sociedade culturalmente atrasada e sexista que se expressava tanto entre os generais de plantão como em uma esquerda intelectualizada cujo melhor representante era justamente o jornal Pasquim, que associava a liberalização dos costumes a uma vulgarização na forma de tratar a mulher e a um constante deboche em relação a tudo que fosse ligado ao feminismo. (2003, p. 64)

As observações de Bernardo Kucinski vão ao encontro desta perspectiva, ao destacarem o rechaço da imprensa alternativa às questões das mulheres.

Enquanto um novo movimento feminista explodia na Europa desde o começo dos anos de 1970, no Brasil a questão da mulher era desprezada por diversos jornais alternativos importantes. [...] No Brasil, o feminismo ainda era tratado com desdém e mesmo chacota, inclusive por $\mathrm{O}$ Pasquim, que fazia o gênero do jornal machista como parte de sua postura geral "anti-classe média moralista", especialmente através dos artigos de Ivan Lessa, Ziraldo e Paulo Francis. Frequentemente, associavam feminismo à frustração sexual. (2003, p. 124)

Este exemplo de um discurso polêmico e repleto de contradições presente na imprensa alternativa reforça a necessidade do movimento feminista criar seus próprios veículos naquele período, reconhecendo a importância de valorizar um discurso em que havia espaço para causas específicas das mulheres. No artigo O Sistema percebeu a força explosiva do movimento feminista e se assustou, Carmem da Silva denuncia o silenciamento do feminismo na mídia.

Enquanto se tratava apenas de melhorar o relacionamento do par, mas sem questionar o casamento; de criar mais harmonia entre as gerações, mas sem contestar a família nem o princípio de autoridade; de incitar a mulher a trabalhar "para realizar-se", mas sem competir no campo econômico, tudo bem com a imprensa em geral. Enquanto se tratava de reivindicações exclusivamente sociais, válida para ambos os sexos (por exemplo, igualdade salarial, etc), tudobem com a imprensa alternativa de esquerda. Mas feminismo propriamente dito, em toda extensão de suas propostas, é tema sutilmente censurado nos órgãos de comunicação. (1983, p. 30) 
Mesmo diante de todas as limitações e impasses para o desenvolvimento de uma imprensa propriamente feminista, pode-se dizer, ao observarmos os jornais publicados entre os anos 1970 e 1980, que as diversas experiências de comunicação que marcaram a história do movimento revelam a mídia alternativa como um lugar de resistência e construção de identidades, uma vez que o discurso projetado nos veículos constitui também um fazer/agir do feminismo, que conquista espaço na esfera pública a partir de suas estratégias de visibilidade.

Em outros termos, percebe-se que a mídia alternativa traduz e participa do processo de legitimação do movimento no período da ditadura, produzindo discursos que passam a incorporar a luta pelos direitos das mulheres, seja nas ruas ou no espaço doméstico. São páginas de uma resistência que tenta fazer ecoar as mais diversas expressões de desigualdade, em meio a um contexto pautado por lutas políticas pela democracia.

\section{Referências}

BARSTED, Leila Linhares. Comunicação: é falando que a gente se entende. In: PROJETO MULHER. Mulheres em Movimento. Rio de Janeiro: Editora Marco Zero; Instituto de Ação Cultural,1983. p. 13-16.

BORBA, ngela. Sociedade Brasil-Mulher. In: PROJETO MULHER. Mulheres em Movimento. Rio de Janeiro: Editora Marco Zero; Instituto de Ação Cultural,1983. p. 198-199.

BORGES, Adélia. Jornal Mulherio. In: PROJETO MULHER. Mulheres em Movimento. Rio de Janeiro: Editora Marco Zero; Instituto de Ação Cultural,1983. p. 22-24.

CARDOSO, Elizabeth. Imprensa brasileira pós-1974. Revista Estudos Feministas. Florianópolis: CFH/CCE/UFSC. V. 12, n. especial, 2004. p. 37-55.

FARRELL, Amy Erdman. A Ms. Magazine e a promessa do feminismo popular. São Paulo: Editora Barracuda, 2004.

FESTA, Regina. Comunicação popular e alternativa no Brasil. São Paulo: Paulinas, 1986.

KUCINSKI, Bernardo. Jornalistas e revolucionários nos tempos da imprensa alternativa. São Paulo: Scritta Editorial, 1991.

LEITE, Rosalina de Santa Cruz. Brasil Mulher e Nós Mulheres: origens da imprensa feminista brasileira. Revista Estudos Feministas. CFH/CCE/UFSC. Vol. 11, n. 1, 2003. p. 234-241.

PEDRO, Joana Maria. Narrativas fundadoras do feminismo: poderes e conflitos (19701978). Revista Brasileira de História. São Paulo, Anpuh, n.52, vol. 26, 2006. p. 249-272.

PERROT, Michelle. As mulheres ou os silêncios da história. Bauru: Edusc, 2005. 
Abramo, 2003.

SILVA, Carmem da. "O Sistema percebeu a força explosiva do movimento feminista e se assustou". In: PROJETO MULHER. Mulheres em Movimento. Rio de Janeiro: Editora Marco Zero; Instituto de Ação Cultural,1983. p. 28-30.

TELES, Maria Amélia de Almeida. Breve história do feminismo no Brasil. São Paulo: Brasiliense, 1999.

WOITOWICZ, Karina Janz. "Lutas e vozes das mulheres na imprensa alternativa: a presença do feminismo nos jornais Opinião, Movimento e Repórter na década de 1970 no Brasil”. In: WOITOWICZ, Karina Janz (org.). Recortes da mídia alternativa: histórias \& memórias da comunicação no Brasil. Ponta Grossa: Editora UEPG, 2009. p. 31-48.

Este artigo e todo o conteúdo da Estudos em Jornalismo e Mídia estão

disponíveis em https://periodicos.ufsc.br/index.php/jornalismo

Estudos em Jornalismo e Mídia está sob a Licença Creative Commons 2.5 